BMJ Open Sport \& Exercise Medicine

\section{'I always considered I needed injury prevention to become an elite athlete': the road to the Olympics from the athlete and staff perspective}

Oriol Bonell Monsonís, ${ }^{1}$ Evert Verhagen (1) , ${ }^{2}$ Jean-Francois Kaux, ${ }^{3}$ Caroline Bolling ${ }^{2}$

To cite: Bonell Monsonís 0 , Verhagen E, Kaux J-F, et al. 'I always considered I needed injury prevention to become an elite athlete': the road to the Olympics from the athlete and staff perspective. BMJ Open Sport \& Exercise Medicine 2021;7:e001217. doi:10.1136/ bmjsem-2021-001217

Accepted 22 November 2021

Check for updates

C) Author(s) (or their employer(s)) 2021. Re-use permitted under CC BY-NC. No commercial re-use. See rights and permissions. Published by BMJ.

${ }^{1}$ Department of Movement Sciences, Department of Epidemiology, Maastricht University, Maastricht, Netherlands

${ }^{2}$ Amsterdam Collaboration on Health \& Safety in Sports, Department of Public and

Occupational Health, Amsterdam Movement Sciences, Amsterdam UMC, University Medical Centres - Vrije Universiteit Amsterdam, Amsterdam, Netherlands ${ }^{3}$ Physical Rehabilitation Medicine and Sports Traumatology Department, SportS2, University of Liège and University Hospital of Liège, French-speaking Research Network for Athlete Health Protection \& Performance (ReFORM), Liège, Belgium

Correspondence to Professor Evert Verhagen; e.verhagen@amsterdamumc.nl

\section{ABSTRACT}

In this study, we explored the perspectives about sports injury prevention of Belgium Olympic level athletes, coaches, managers and healthcare providers from various Olympic sports. We conducted a qualitative study, including 17 semistructured interviews. All interviews were transcribed verbatim and analysed by two independent coders through constant comparative data analysis based on Grounded Theory principles. Our findings overview the athlete's journey to becoming an elite athlete, and how an elite sports context influences and modulates injury prevention practice at this level. Participants described an elite athletic career as a continuous and adaptive evolving process. According to athletes and all stakeholders, sports injury prevention is a learning process shaped by individual experiences. This embodiment provides athletes with insight into the importance of ownership of their bodies and self-awareness. Thus, experience, communication, empowerment, knowledge, education, the elite athlete context and sports culture, all play a fundamental role in sports injury prevention. Our findings support the importance of contextual factors in sports injury prevention in an elite sports context. These results also bring practical implications on how we should approach injury prevention differently along an athlete's journey to becoming an elite athlete. Considering specific contextual factors and influencing the process through awareness, communication and a shared responsibility is essential to develop a healthy and successful athlete.

\section{INTRODUCTION}

Elite athletes coexist in a performance-driven environment in which the aim is to increase sports performance. In such a context, there is a substantial risk of sports injuries, ${ }^{1}$ which directly impacts the athlete's ability to perform. $^{23}$ As a consequence, injury prevention plays a crucial role in the context of elite sport. ${ }^{4}$ With a growing research interest in the field over the last decades, we now have access to diverse and efficacious injury prevention strategies within various sports. ${ }^{15}$ However, the adoption of these measures in elite sports

\section{Key messages}

What are the new findings

- Qualitative methods can be applied to understand injury prevention as a complex and dynamic system and gain insight into the role of contextual factors and their interactions in sports injury prevention.

- Contextual factors greatly influence the athlete's journey towards becoming an Olympic level athlete.

- Awareness, exposure and guidance regarding injury prevention in the early stages of an athlete's career can impact future preventive behaviour and athletic success.

How might it impact clinical practice in the future

- Injury prevention demands engagement and empowerment of multiple stakeholders who should communicate openly and share responsibilities.

- Experience plays a crucial role in athletes' careers and how athletes and their staff perceive and deal with injury prevention. This learning process contributes to shaping sports injury prevention strategies.

- The approach to develop and sustain injury prevention strategies for less or more experienced athletes should be tailored according to their different demands, maturity level, knowledge and ownership of their careers.

is limited, and the results presented in studies are not commonly translated into practice. ${ }^{6-9}$

Likewise, we know that the challenges to prevent injuries are also related to the complex nature of the problem, which requires a better understanding of the injury in a specific sport-related context. ${ }^{4}{ }^{10-12}$ So, to successfully implement sports injury prevention interventions, it is fundamental to investigate the context of injuries and give voice to stakeholders. ${ }^{41314}$ The perspectives of athletes, coaches, and healthcare providers can provide insights to improve injury prevention. ${ }^{15-17}$ Yet, these views are currently under-represented in the literature. ${ }^{18}$ Findings from qualitative research 
indicate that coaches, health professionals and athletes acknowledge the importance of injury prevention as a means to achieve the best performance, taking into consideration their elite sport context. ${ }^{19-21}$ However, the preventive measures described in such studies are related with open and effective communication, teamwork and empowering athletes rather than the exercise-based interventions widely documented in our literature. ${ }^{22} 23$ Qualitative research methods ${ }^{424}$ provide insight into the meaning and understanding of the contextual factors and can help us understand how and why injury prevention is adopted (or not) in the context of elite sports. ${ }^{41522}$ Thus, identifying these aspects may benefit the adoption of injury prevention strategies and lead to more contextdriven prevention measures. Therefore, this qualitative study aimed to explore perspectives around sports injury prevention of Belgian Olympic level athletes, coaches, and healthcare providers.

\section{METHODS}

\section{Study design}

This study used a qualitative research design based on grounded theory (GT) principles ${ }^{2526}$ focusing on building new theories from data, involving an inductive approach. Our analysis intended to address processes and interactions by interpreting and generating connections from multiple perspectives and participants' realities within an interpretive paradigm. ${ }^{27}$ Results are reported according to the Consolidated Criteria for Reporting Qualitative Research. ${ }^{28}$

\section{Participants}

The participants in this study were elite athletes and their respective coaches, team managers and medical staff representing the Belgian Olympic and Interfederal Committee. A contact person (J-FK) from the IOC Research Centre from Belgium (from French-speaking Research Network for Athlete Health Protection \& Performance, site of
Liège, Belgium) contacted the sports federations which provided the contacts of the participants. All potential participants were first contacted through an invitation email containing an information letter. After acceptance to participate, they were contacted by the research team. All participants had to be Olympic level athletes or staff, who either participated in the previous Olympic Games were available for selection or had already qualified for the upcoming Olympic Games.

Our aim was to include a heterogenic group of participants. Therefore, a maximum variation sampling method $^{29}$ was adopted and our contact person had instructions to recruit a diverse sample. Consequently, we included young and experienced participants from different individual and team sports. While this provided us with various perspectives, backgrounds and experiences.

\section{Data collection}

Data were collected through online semi-structured interviews between March and May 2020. All interviews were conducted in English by CB. The mean length of the interviews was $33 \mathrm{~min}$ (range $23-47 \mathrm{~min}$ ). The topic list is presented in table 1. After 17 interviews, the same constructs were repeated, and no additional new themes emerged from the data, indicating that saturation had been reached..$^{30}$

\section{Data analysis}

All interviews were audiorecorded and transcribed verbatim and further inductively analysed based on constant comparative data analysis, ${ }^{31} 32$ employing principles of GT.

In the first stage, two researchers ( $\mathrm{CB}$ and $\mathrm{OBM}$ ) independently open-coded seven interviews, using the ATLAS.ti software (Scientific Software Development, Berlin, Germany; V.8.4.5). Subsequently, codes and memos were discussed, and researchers refined the

Table 1 Topic list and interview questions

\begin{tabular}{|c|c|}
\hline Topic & Questions \\
\hline Injury definition & $\begin{array}{l}\text { 1. Which aspects do you consider defining a sports injury? (Symptoms? Time? Training modification? Need of } \\
\text { medical care?) }\end{array}$ \\
\hline \multirow[t]{2}{*}{ Factors influencing injury } & 2. Which factors influence the occurrence of an injury? \\
\hline & 3. How can these factors affect the occurrence of an injury? \\
\hline \multirow[t]{2}{*}{ Believes in injury prevention } & 4. Do you believe that injuries can be prevented? \\
\hline & 5. How can injuries be prevented? \\
\hline \multirow[t]{4}{*}{ Injury prevention strategies } & 6. Which injury prevention strategies do you apply? Why do you apply these strategies? \\
\hline & 7. What do you consider when choosing the injury prevention strategies that you currently use? \\
\hline & 8. How do you choose each strategy to apply, and why do you choose them? \\
\hline & 9. What motivates you to apply an injury prevention strategy? \\
\hline \multirow{3}{*}{$\begin{array}{l}\text { Influence of the context and } \\
\text { sport culture }\end{array}$} & 10. How does the context of elite sports/your own reality influences injury prevention (facilitators and barriers)? \\
\hline & 11. How does your sports culture/elite sports structure nationwide influence the way that you prevent injuries? \\
\hline & $\begin{array}{l}\text { 12. Which factors in your daily routine support injury prevention? Which factors make injury prevention more } \\
\text { difficult? }\end{array}$ \\
\hline
\end{tabular}


analysis by merging related codes into categories and making connections between codes. Once consensus was reached, OBM coded the remaining interviews $(n=10)$. $\mathrm{CB}$ and $\mathrm{OBM}$ discussed the emergent findings over two meetings and presented an overview to $\mathrm{EV}$, who was unfamiliar with the interviews. In the same meeting between the three researchers (OBM, CB and EV), codes, categories and discrepancies were discussed and compared until agreement was reached. Consequently, the preliminary results of the analysis were developed by developing the main concepts of the analysis. Finally, a diagram was developed to illustrate the athlete's journey with the main topics and their interconnections with injury prevention.

\section{Patient and public involvement}

Patients and/or the public were not involved in the design, or conduct, or reporting, or dissemination plans of this research.

\section{RESULTS}

Seventeen interviews were conducted with eight athletes, three managers, two coaches, two physical therapists, one medical doctor and one strength and conditioning coach (S\&C). Participants were working in basketball, judo, athletics and equestrian sports. To guarantee confidentiality, no further details will be provided on demographics. Our findings are presented according to the main themes and the respective codes and quotes available on the tables.

\section{Shaping injury prevention behaviours}

Participants defined injury as an event that prevents them from performing independently of any pain perceived (table 2). Athletes and staff reported that biomechanical, physiological, psychological and contextual factors could influence injury (table 3). However, the main preventive interventions detailed by participants focused on exercisebased strategies, performed primarily during the warm-up. Additionally, recovery strategies, nutrition, staying physically and mentally healthy, and managing training loads were reported. Furthermore, some athletes acknowledged the importance of visiting physiotherapists periodically. Preseason assessments were mentioned to identify any weaknesses and risk factors to be addressed during the season.

Athletes and staff mentioned that they choose the injury prevention strategies based on experience and what athletes liked or, as an athlete stated, on 'what makes me feel good'. Also, physiotherapists and S\&C coaches choose their recommended interventions considering the scientific evidence and their own experiences.

Staff members recognised the importance of planning, organisation and the potential 'marginal gains' when considering the smaller details as part of injury prevention and performance. The latter is the ultimate goal in elite sports.

\section{We learn by doing: the power of experience}

Sports injury prevention was regularly mentioned as a learning process influenced by an athlete's experience (table 4). This experience was mostly associated

Table 2 Themes, subcodes and exemplary quotes on injury prevention behaviours

\begin{tabular}{|c|c|c|}
\hline Main theme & Subcode & Exemplary quote \\
\hline Injury definition & $\begin{array}{l}\text { Impact on } \\
\text { performance and } \\
\text { dealing with pain }\end{array}$ & $\begin{array}{l}\text { Athlete 01: "For me, it is when I cannot perform anymore." } \\
\text { Manager 02: "For me, an injury is when the athlete cannot perform as he usually does and } \\
\text { cannot perform at his best". } \\
\text { Physical therapist 02: "A sports injury stops the athlete from practising or playing." } \\
\text { Athlete 06: "For me, when I have pain, I am not injured because I can keep going." } \\
\text { Medical doctor: "The problem with high-level sports and pain is difficult, because when you } \\
\text { practice sport at a high level it is usual that you have pain during your training and so on." } \\
\text { Coach 01: "I think that every professional player plays hurt, with a knee, ankle, neck or muscles. } \\
\text { I think that is normal. It is a habit. It is normal to play with that." } \\
\text { Coach 02: "I think for the professional player it is the worst thing." }\end{array}$ \\
\hline \multirow[t]{3}{*}{$\begin{array}{l}\text { Injury prevention } \\
\text { strategies }\end{array}$} & Physiotherapist's role & $\begin{array}{l}\text { Athlete 03: "I think that if I am not doing (going to the physio) that I have more chance to have } \\
\text { an injury or not to be able to perform at my best." } \\
\text { Athlete 05: "It is him (physiotherapist) who explained to me, he knows my body for many years, } \\
\text { and he knows what I need to work on or if I get pain there, he says "you should do this or that". } \\
\text { Then, these exercises are to help it for sure." }\end{array}$ \\
\hline & $\begin{array}{l}\text { Multiple criteria for } \\
\text { injury prevention } \\
\text { measures }\end{array}$ & $\begin{array}{l}\text { Physical therapist 02: "I think respecting the experience of the players and also the literature to } \\
\text { follow-up." } \\
\text { Athlete 01: "Mainly what makes me feel good. So, you know, throughout the years you've been } \\
\text { working with so many different people,(...)but then you go on your own, and you find somebody } \\
\text { in the area and like from every person you take, I took something or sometimes nothing.(...) } \\
\text { Then you try that and then see, ok, this feels good. It is really a little bit my own research I had } \\
\text { to do to get where I am." } \\
\text { Athlete 06: "So, actually, I am just following his advice (physiotherapist) because I felt good." }\end{array}$ \\
\hline & Marginal gains & $\begin{array}{l}\text { Medical doctor: "I think that there are so many parameters to take into account, especially for } \\
\text { professional or high-level sportsmen because they sometimes need nearly nothing to win the } \\
\text { gold, and sometimes there are only a few things to improve their performances." } \\
\text { Manager 01: "But we are looking at marginal gains. Marginal gains mean everything.(...)We try } \\
\text { to limit those risks as much as possible." }\end{array}$ \\
\hline
\end{tabular}


Table 3 Themes, subcodes and exemplary quotes on responsibilities and elite athlete's context

\begin{tabular}{|c|c|c|}
\hline Main theme & Subcode & Exemplary quote \\
\hline \multirow[t]{2}{*}{ Responsibilities } & $\begin{array}{l}\text { The athlete is the } \\
\text { main accountable }\end{array}$ & $\begin{array}{l}\text { Physical therapist } 01: \text { "The athlete first, I think he is the first to be responsible for his career." } \\
\text { Coach 01: "The first responsibility is the player. It is the player who needs to take care of his body } \\
\text { or her body because it is work." } \\
\text { Athlete 01: "It is more a responsibility for me, it is what I owe, like they give me a contract, I need } \\
\text { to do everything possible to stay healthy, to be the best athlete, to be ready physically, mentally, } \\
\text { on every aspect. So, I really take it upon me to get there." }\end{array}$ \\
\hline & $\begin{array}{l}\text { Teamwork and a } \\
\text { supporting role } \\
\text { from staff }\end{array}$ & $\begin{array}{l}\text { Medical doctor: "I think the athlete has to be really part of this decision too because if you don't } \\
\text { care it is not possible to work correctly and also the doctor, the physiotherapist, the strength and } \\
\text { conditioner, the trainer, the coach. So, I think it is a team decision." } \\
\text { Manager 01: "Everybody that we have in the staff is responsible to prevent injuries." } \\
\text { Athlete 04: "I think now I feel like I have a complete team surrounding me, and before that wasn't } \\
\text { really the case.(...). And I feel like now there is a good team with good communication helping } \\
\text { each other out and, in the end, helping me out and making me feel comfortable and confident." }\end{array}$ \\
\hline \multirow[t]{3}{*}{ Elite context } & $\begin{array}{l}\text { Facilitates } \\
\text { preventing injuries }\end{array}$ & $\begin{array}{l}\text { Medical doctor: "I think it is easier to do injury prevention because of the staff you have. You } \\
\text { normally have more money to do that. So, I think it is easier." } \\
\text { Manager 01: "All that culture around the professional coaching facilitates the injury prevention. } \\
\text { That is for me basically what it is." } \\
\text { Athlete 01: "I haven't had any major injuries, so I feel like part of that is because I am being } \\
\text { monitored and managed by different people, and they are telling me what to do and how to train } \\
\text { better." }\end{array}$ \\
\hline & $\begin{array}{l}\text { Easier to get } \\
\text { injured }\end{array}$ & $\begin{array}{l}\text { Athlete 04: "It is easier for us to get injured because we go to those limits, and we look up the } \\
\text { limits, so I think it is a lot easier for us to get injured." } \\
\text { Medical doctor: "I believe it is possible to prevent injuries, but the risk=0 does not exist anymore." }\end{array}$ \\
\hline & $\begin{array}{l}\text { Role of staff } \\
\text { members }\end{array}$ & $\begin{array}{l}\text { Physical therapist 02: "I think everybody has like an important role and are partners because they } \\
\text { make really a difference.(...)So, everybody knows his role, I think that is very important." } \\
\text { Manager 02: "They have a person taking care of social media, they have a person taking care } \\
\text { of their food, their intervention, their training, the planning.(...)it is a whole group around them } \\
\text { because you can't do this alone. Because I say individual sport, but it is a team sport." }\end{array}$ \\
\hline
\end{tabular}

with the years of being an elite athlete and the lessons learnt through previous injuries. Throughout this process, athletes gained more knowledge. Athletes raised awareness and acknowledged the importance of injury prevention by taking care of and listening to their bodies, which allowed them to push their limits more 'consciously'. Moreover, the participants repeatedly compared their current injury prevention behaviour with their early career, commenting about how they had become more aware of and proactive in implementing sports injury prevention measures.

Previous injury and avoiding the consequences were noted as the main motivations to practice injury prevention strategies, again showing the importance of experience. Some staff members were former athletes and mentioned that their previous experience could benefit their athletes. Also, once athletes reached the elite level, they considered being an athlete their job and preventing injuries their responsibility.

\section{Responsibilities and the influence of elite athlete's context}

All participants considered the athlete the main responsible person for preventing injuries, but they also stated the supporting role from the stakeholders (table 3). Likewise, athletes and staff members mentioned the importance of teamwork and shared responsibility to prevent injuries.

All participants recognised that an elite context entails athletes being surrounded by a qualified and specialised group of professionals, sometimes chosen by athletes themselves. This promotes a sports culture of injury prevention. However, athletes admitted they were more susceptible to injury due to their high physical demands, which provide a greater focus on injury prevention. Being an elite athlete places more responsibility on the individual, leading to more available resources for injury prevention and a more comprehensive team around the athlete with easier access to medical care.

\section{Communication within the team as a cornerstone}

Reinforcing the value of teamwork, open and effective communication between all stakeholders was reported to be an important foundation for the injury prevention process (table 5). Constant communication, especially between athletes and coaches and athletes and physiotherapists, was crucial to building trusting relationships. In the particular context of Belgium, participants described the differences between the Flemish and the French-speaking regions regarding the organisation, equipment, facilities, structures, economic resources and interventions implemented, and how eventually these differences influenced injury prevention.

Some issues on communication were mentioned. For example, a participant stated that 'Belgium is different as there are two parts' where 'everything is duplicated'. Moreover, an athlete has a national coach and, often, a personal coach whose visions on injury prevention may differ. Collaboration and open and free communication between these two stakeholders is vital for the athlete's success at all levels. Specifically, the coaches' role in 
Table 4 Themes, subcodes and exemplary quotes on the role of experience

\begin{tabular}{lll}
\hline Main theme & Subcode & Exemplary quote \\
\hline Experience & $\begin{array}{l}\text { Learning process } \\
\text { through time, injuries } \\
\text { and maturation }\end{array}$ & $\begin{array}{l}\text { Athlete 01: "I learned throughout my career, and after some injuries, I have to be really honest and really } \\
\text { careful not to make things worse. Because sometimes it starts with a little thing, and then it just gets } \\
\text { way bigger." } \\
\text { Physical therapist 01: "When they grow older, they see that it is very important because they had one }\end{array}$ \\
$\begin{array}{l}\text { or two injuries, and it is not a good feeling to have an injury(,...), but it is the experience that makes } \\
\text { that. When they have nothing, they don't feel it is important. It is the age, the age, the experience, the } \\
\text { maturation of the athlete." }\end{array}$
\end{tabular}

Gaining knowledge on Athlete 02: "I think the older you get, the more experience you get, the more you read about it and body awareness and know about it, the more it helps you also to get to know your body.(...)So, I think the older you get, the self-regulation more you get to know yourself and to get, like to, make the right decision."

Athlete 03: "With the experience, I know what I need, and I know my body better. So, yeah. I tried a lot of things, and now I can say this is good for me and what I do."

Physical therapist 01: "If you have the knowledge of the risks and about that IP works, then you get the intrinsic motivation to do it."

Staff learning from and
transmitting it to athletes
after being former
athletes

Early career versus current situation

Coach 01: "You know or feel when you are on the floor, you know what thinks a player, you know what

they want(...)because you were a player before, and I think it is an advantage for me. I think it is for me it is a part of the prevention for the injury."

Athlete 04: "Trainers can help as well because they are on the mat with us all the time. They can see maybe things that we don't even feel or see."

Athlete 01: "I worked with so many coaches, but not really one told me the importance of injuries and taking care of my body as I should've."

Athlete 05: "Learning throughout especially the last 2 years, now I am like ok, so this works, and this feels good and(...)sometimes I think back, and it is like I should've known a lot better or a lot more when I was younger, and I could've been further in certain areas of my career."

Athlete 06: "I wish I knew more, and I think I could've prevented a lot more, but you are just young, and you think I have to work hard to get where I am, so that is what I am going to do.(...)I wish I knew more because I really believe that in the prevention of sports injuries, I could have avoided some things, I am sure."

\begin{tabular}{|c|c|c|}
\hline \multirow[t]{2}{*}{ Motivations } & Performance and injury & $\begin{array}{l}\text { Physical therapist 02: "I think most of all the experience of a bad injury, most of the players had already } \\
\text { an injury and(...)that needs an inactivity of several months(...)so they really want to prevent this kind of } \\
\text { injuries." } \\
\text { Manager 01: "As a professional athlete, that aspect alone that "I cannot get injured, I am going to take } \\
\text { care of myself, I am going to listen to everybody,(...)because I want to be in the team to experience all } \\
\text { that". For me, that has to be the motivation." } \\
\text { Athlete 06: "Actually, my goal is always don't miss practices and try not to miss games, and that is the } \\
\text { only thing that drives me, and I want to keep going." } \\
\text { Athlete 07: "I had twice ACL injury so it's a big injury and I was a lot of time sitting out,(...)I know it's } \\
\text { just so important to do this (injury prevention), so I can keep on staying on the court. So that's the main } \\
\text { thing, don't want to be injured." } \\
\text { Athlete 02: "Because I have had so many injuries, I think for me it (injury prevention) is now a must, so I } \\
\text { have to do it." }\end{array}$ \\
\hline & $\begin{array}{l}\text { Being an elite athlete is } \\
\text { a job }\end{array}$ & $\begin{array}{l}\text { Athlete 01: "Well, it is my job now, so I am a professional athlete, so obviously you want to keep doing } \\
\text { this career, you want to keep making money." } \\
\text { Athlete 04: "I think it is a big part of being a top-level athlete, and I think it adds to the professionalism." } \\
\text { Athlete 06: "They pay you, and it is your work." }\end{array}$ \\
\hline
\end{tabular}

injury prevention was related to their communicative skills. Strong communicative skills forged a bond with the athletes through guidance and shared decision making and transmitting coaches' knowledge and experience to their athletes. This ultimately diminished injury risks.

\section{Sports culture evolution and elite context impact on injury prevention}

When athletes and the staff were asked how their elite context influenced their careers and injury prevention, they stated that 'it is evolving' even though there was still work ahead (table 6). The most experienced athletes and staff members who were former athletes constantly compared the early years of their careers with their current situation, underscoring a remarkable evolution in resources, professionalism and specialised care to support the athlete. Participants reflected on these differences in experience, pointing out the need to educate and raise awareness of injury prevention from a young age to make it a habit.

Despite the evolution as mentioned above, certain challenges were mentioned. On the one hand, early in their careers, athletes mentioned having limited body awareness and not taking care of their bodies. Participants highlighted that no or limited injury prevention measures were implemented. At this stage, some athletes recognised that they normally did not engage in any injury prevention strategy until they sustained an injury. For instance, equestrian athletes reported that it was considered as part of the sports culture that riders suffered from back pain, as one rider stated that 'I don't know one rider who doesn't have back pain'. Also, from the staff and community standpoint (ie, federations, clubs), injury prevention was not perceived as a priority in the athletes' daily routine. 
Table 5 Themes, subcodes and exemplary quotes on communication

\begin{tabular}{|c|c|c|}
\hline Main theme & Subcode & Exemplary quote \\
\hline \multirow[t]{3}{*}{ Communication } & Confidence and thrust & $\begin{array}{l}\text { Physical therapist 02: "I think that it's very important the confidence with the medical staff } \\
\text { members because (the athletes) they would even call us if they feel something is wrong... } \\
\text { and tell to the physio or the doctor of the team at that moment. You see that they have a } \\
\text { lot of confidence. That's cool. Of course.(...)Yeah, confidence is one of the most important } \\
\text { things. And if the athlete doesn't trust you, forget it." } \\
\text { Athlete 05: "I think these people (health care providers), they know what they are doing, they } \\
\text { have studied this, and they know best what to do and how to treat it." } \\
\text { Manager 02: "We do have to have a relationship of full trust, and then only can they talk to } \\
\text { us and let us know how they feel and how their body is and how they need to work on some } \\
\text { things. Then I can talk about injury prevention. But if you don't have this relationship of trust, } \\
\text { they will not open, and they will close." }\end{array}$ \\
\hline & $\begin{array}{l}\text { How the Belgian context } \\
\text { affects communication }\end{array}$ & $\begin{array}{l}\text { Medical doctor: "In Belgium, everything is difficult because as you know the country is } \\
\text { divided into two parts, the Flemish in the north they speak Dutch, the Wallonia in the south } \\
\text { they speak French and also the east part they speak German. And everything is duplicated. } \\
\text { We usually have one national federation, but two different leagues and these leagues } \\
\text { organise follow-up of the athletes. And the leagues have the money for the medical follow- } \\
\text { up of the athletes and the prevention for the athletes, and sometimes the north and south } \\
\text { are different.(...)They have much more money in the north for sports than in the south." } \\
\text { Manager 03: "It is very different because they have different budgets, different ministries. It is } \\
\text { like two countries." } \\
\text { Athlete 08: "In Belgium, there are two sides(...)I was on the Flemish side, but I changed, and } \\
\text { now I am on the French-speaking side, and the structures are completely different." } \\
\text { Athlete 04: "it is crazy, and the focus is completely different, and I feel like the French side } \\
\text { is a lot more professional, but it depends on who you are asking. Some people like it, and } \\
\text { some people don't like it, I think that is the way it is, but when I was younger, on the Flemish } \\
\text { side there wasn't a lot of injury prevention or a lot of structure from the federation." } \\
\text { Strength and conditioning coach: "I work with the French riders, but I don't know the Dutch } \\
\text { part because Belgium is a difficult country.(...)I don't have contact with the national team. I } \\
\text { just have contact with the French part of the federation." }\end{array}$ \\
\hline & $\begin{array}{l}\text { Coach's role in injury } \\
\text { prevention }\end{array}$ & $\begin{array}{l}\text { Coach 01: "My job is to feel them, to see the attitude(...)because then they have pain, they } \\
\text { have no pain, maybe they are hurt, but they don't want to say it because they are afraid, and } \\
\text { I think that is the power of that job for the prevention of injuries." } \\
\text { Physical therapist 01: "And to hear the coach and to follow the counsel, to follow what we } \\
\text { say and not to do what they want only." } \\
\text { Athlete 07: "So, I really think that you have the head coach who is always the boss, but next } \\
\text { there should be a physio, a physical coach, a team who actually advises and I think for head } \\
\text { coaches it is important to learn, to listen to these people." }\end{array}$ \\
\hline
\end{tabular}

Thus, all stakeholders advocated the importance of improving facilities and organisational structures and implementing injury prevention strategies for athletes. Furthermore, according to participants, improvements in education and awareness on prevention (to young athletes and all stakeholders) would impact injury prevention and performance. Moreover, it was mentioned that sports popularity and success in international competitions influence the availability of economic resources and personnel.

The lack of a comprehensive nationwide structure was also mentioned as part of the context. This limitation can impact the recovery time. For example, some athletes had to travel for more than an hour between their home and training facility. On the other hand, the top sport school system (National programme for talented young athletes) was mentioned as a relevant structure at the beginning of athletes' careers.

\section{Becoming an Olympic level athlete}

From early on in their careers, experience played a leading role in athletes' careers, influencing their knowledge, motivations and responsibilities on injury prevention. Thus, sports culture, experience, communication, empowerment, knowledge, education and the elite athlete context play a fundamental role in sports injury prevention. Additionally, their experiences guided them through their sports journey to contribute to their preventive strategies. The team around the athlete also evolves along the process, making communication and trusted relationships essential for shared-decision making. The preventive strategies are developed based on motivations, knowledge, evidence and the athletes' opinion of what 'feels good' for them. The evolution of injury prevention itself is influenced by the constructs of the journey (sports culture, experience, team and context). By the time athletes reached the elite level, they had more resources and a better supporting structure in general. Becoming an elite athlete was the endpoint of the process; it comes with a higher risk of injury and brings more responsibility because it is a job. This embodiment provides athletes with insight into the importance of ownership of their bodies and self-awareness. Figure 1 depicts this development process from young athletes to elite athletes as a visual summary of our results. 
Table 6 Themes, subcodes and exemplary quotes on ongoing evolution in sports culture on sports injury prevention

\begin{tabular}{|c|c|c|}
\hline Main theme & Subcode & Exemplary quote \\
\hline $\begin{array}{l}\text { Changes in sports } \\
\text { culture }\end{array}$ & More resources & $\begin{array}{l}\text { Manager } 03: \text { "Yes, because now they have a medical staff and before that didn't exist, and it is all, } \\
\text { now } 2 \text { years ago that they really do prevention on the injuries." } \\
\text { Coach } 02: \text { "Now all these facilities are definitely a lot better than it was } 30-40 \text { years ago, and that } \\
\text { is why also there we have just because of that already less injuries now than early on." } \\
\text { Strength and conditioning coach: "I think that now the federation is trying to change and to } \\
\text { implicate, improve.(...) think it is better now. It is better than when I started with the federation. } \\
\text { They understand the importance of physical work and the prevention." }\end{array}$ \\
\hline
\end{tabular}

Adding

professionalism

Athlete 05: "I think how the sport is now; it is becoming more and more professional. It also means that we have to take much more care about ourselves."

Athlete 07: "But for sure the last few years, the professionalism in the national team really grew up. So, I think you have a lot more people that will help you, and you can always ask them to help you."

Coach 02: "So, that is why I think that at the moment, the people, riders, trainers, (and staff) concentrate more on training with less risk of injuries than it was many years ago."

\begin{tabular}{|c|c|}
\hline $\begin{array}{l}\text { More people around } \\
\text { the athlete }\end{array}$ & $\begin{array}{l}\text { Physical therapist 01: "I was myself a judoka, but when I was young, there was no physio. When } \\
\text { you were injured, you didn't say it(...). But now it is more, it is good, it is better. So, there is a } \\
\text { change. There are more people around the athlete." } \\
\text { Manager 02: "The evolution in professionalism is really when you compare it to } 20 \text { years ago it was } \\
\text { a hobby and even if it was top sport at that moment, if you compare it then to now, the crew that } \\
\text { these guys have around them, the people taking care of, it is terrible. You know, it is like maybe } \\
\text { almost a rock star." } \\
\text { Athlete 07: "I think our better results helped to have more money, and now we have more people } \\
\text { that are helping us } 5 \text { years ago(...)there was no money to do this, we had only one physio, and I } \\
\text { don't even know if we had a physical coach." }\end{array}$ \\
\hline $\begin{array}{l}\text { Age, generational } \\
\text { changes and passing } \\
\text { of time }\end{array}$ & $\begin{array}{l}\text { Medical doctor: "Now I think the culture is evolving, especially for the last } 10-15 \text { years. I think that } \\
\text { the IOC gives this prevention to take care of the athletes, (which) is very important for them." } \\
\text { Coach 02: "I think that the sport always develops because when I early on was talking about my } \\
\text { own sports career, the sport } 40 \text { or } 30 \text { years ago, I still was competing } 20 \text { years ago, was different } \\
\text { than it is now." } \\
\text { Athlete 08: "In that way, I think there is getting a more tendency that people get aware of it, you } \\
\text { know. Let's say } 5 \text { years ago, I wouldn't say any, and now people who are doing the top sport are } \\
\text { aware that it is necessary to have somebody to help you with injury prevention(...)I think it is, but } \\
\text { still on a very low level." }\end{array}$ \\
\hline
\end{tabular}

$\begin{array}{ll}\text { Education on injury } & \text { Educate and raise } \\ \text { prevention } & \text { awareness on young } \\ & \text { athletes }\end{array}$

Athlete 01: "I wish I knew a lot more than I know now when I was younger because I did have a lot

of really serious injuries that I believe(...)they could have been prevented if I was, from a younger age, monitored right because I didn't know."

Athlete 05: "But now it is to try to teach, to make the riders know that it is very important to work on it before you have pain.(...)Like me, I am doing now quite a bit because I feel like I have to." Manager 01: "You cannot reach that level of performing in your sport if during your younger years you were not educated in the right way surrounding injury prevention in the whole scale."

$\begin{array}{ll}\text { Challenges on } & \text { Lack of awareness } \\ \text { injury prevention } & \text { and engagement }\end{array}$

Manager 01: "That is something in my opinion that still has to evolve in the heads of everybody involved. That part is just a crucial part of it that it is better to spend some of your practice time on those kinds of things to get a better result which takes a little more time. That is true. It is an investment, return on investment, but if you don't do it, that's a little bit a problem."

Athlete 07: "Now it's ok, but in the beginning, I felt a little bit lost, and I went asking everywhere, and you don't really know what it's best. So, it's a process of searching."

\begin{tabular}{lll} 
Lack of interest & $\begin{array}{l}\text { Medical doctor: "Because in some sports they don't care about prevention and they don't want it, } \\
\text { even in the international federation." } \\
\text { Athlete 06: "Because I don't have like, really, problems. You know, I feel good, so I go, and I } \\
\text { am ready. Like, I don't have pain, I feel nothing, so I just can go. When my hamstring is sore or } \\
\text { something, then I will stretch for sure a little bit before practice." }\end{array}$ \\
$\begin{array}{ll}\text { Aspects to } \\
\text { improve }\end{array}$ & $\begin{array}{l}\text { Improving facilities } \\
\text { and organisation }\end{array}$ & $\begin{array}{l}\text { Manager 01: "We work with kids from the age of 12(...)in the schools we have full-time coaches, } \\
\text { physical coaches, physios and everything. So, we start educating them very intensely on all these } \\
\text { things." }\end{array}$ \\
& $\begin{array}{l}\text { Manager 02: "We also get a lot of help from the Olympic Committee. We get special days where } \\
\text { we can go as a federation, and then they are going to give us tools to do injury prevention, to have } \\
\text { a good warming up, what to do if you have an injury, so we get a lot of help from these structures." } \\
\text { Athlete 03: "When I was in the US, I just went to training, but before starting, I was in the room } \\
\text { to chill with my teammates, and we stretched, we were with the physio, and I had a massage or } \\
\text { stretching. It is that I don't have here (Belgium) and also after the training, for example in Belgium I } \\
\text { can't really take an ice bath or go to the physio." }\end{array}$ \\
\hline
\end{tabular}

Continued 
Table 6 Continued

\begin{tabular}{|c|c|c|}
\hline Main theme & Subcode & Exemplary quote \\
\hline & $\begin{array}{l}\text { Convince and } \\
\text { educate all } \\
\text { stakeholders }\end{array}$ & $\begin{array}{l}\text { Medical doctor: "For the athlete, we have to discuss with them to explain what the goals are, the } \\
\text { aim of this evaluation. We have to convince them that it is better to avoid injuries, to avoid loss of } \\
\text { time for competition preparation or training and also I discuss that with them, but it is not always } \\
\text { easy for them to understand." } \\
\text { Strength and conditioning coach: "So, it is education. It is after some injury that they understand } \\
\text { that it is important.(...)If I see them after injury or after some pain problem and I work with them } \\
\text { on this part, and they feel that it is better after their mind changes(...)they can work alone on this } \\
\text { because they don't want to have some problem after. So, I think it is like that they understand it." } \\
\text { Athlete 01: "But for me, I really need to be explained why it is important and why we are doing } \\
\text { something." }\end{array}$ \\
\hline Context of Belgium & $\begin{array}{l}\text { Recent } \\
\text { accomplishments as } \\
\text { a turning point }\end{array}$ & $\begin{array}{l}\text { Athlete 07: "I think our better results helped to have more money, and now we have more } \\
\text { people that are helping us. I think } 5 \text { years ago we were not on the European Championships (of } \\
\text { Basketball), and there was no money to do this." } \\
\text { Coach 01: "5 years ago, nobody cared for the Belgian Cats (Women Basketball National team). We } \\
\text { didn't know that we had a team.(..)Now when you speak about the Cats, everybody knows the } \\
\text { Cats because we were at the World Championship, we are the first basketball team that goes to } \\
\text { the Olympics, we are on tv. So, it is great." } \\
\text { Coach 02: "When I took over the Belgium Equestrian team, it was in the second division.(...)so, the } \\
\text { first aim was to get up from second division to first division. We did in the first year(...), and then in } \\
\text { the second year, we jumped all the first division nation cups and big shows. We won the Nations } \\
\text { Cup final, and last year, we became European champions." }\end{array}$ \\
\hline
\end{tabular}

\section{DISCUSSION}

This qualitative study captured perspectives from athletes, coaches, managers and healthcare providers regarding fundamental factors on injury prevention strategies in the Olympic level sports context. Our findings overview the athlete's journey to becoming an elite athlete and how the elite sports context influences and modulates injury prevention practice.

\section{Experience defines an athlete's journey}

Our findings show that preventive behaviours are built on athletes' experiences. Experiences guided a constant

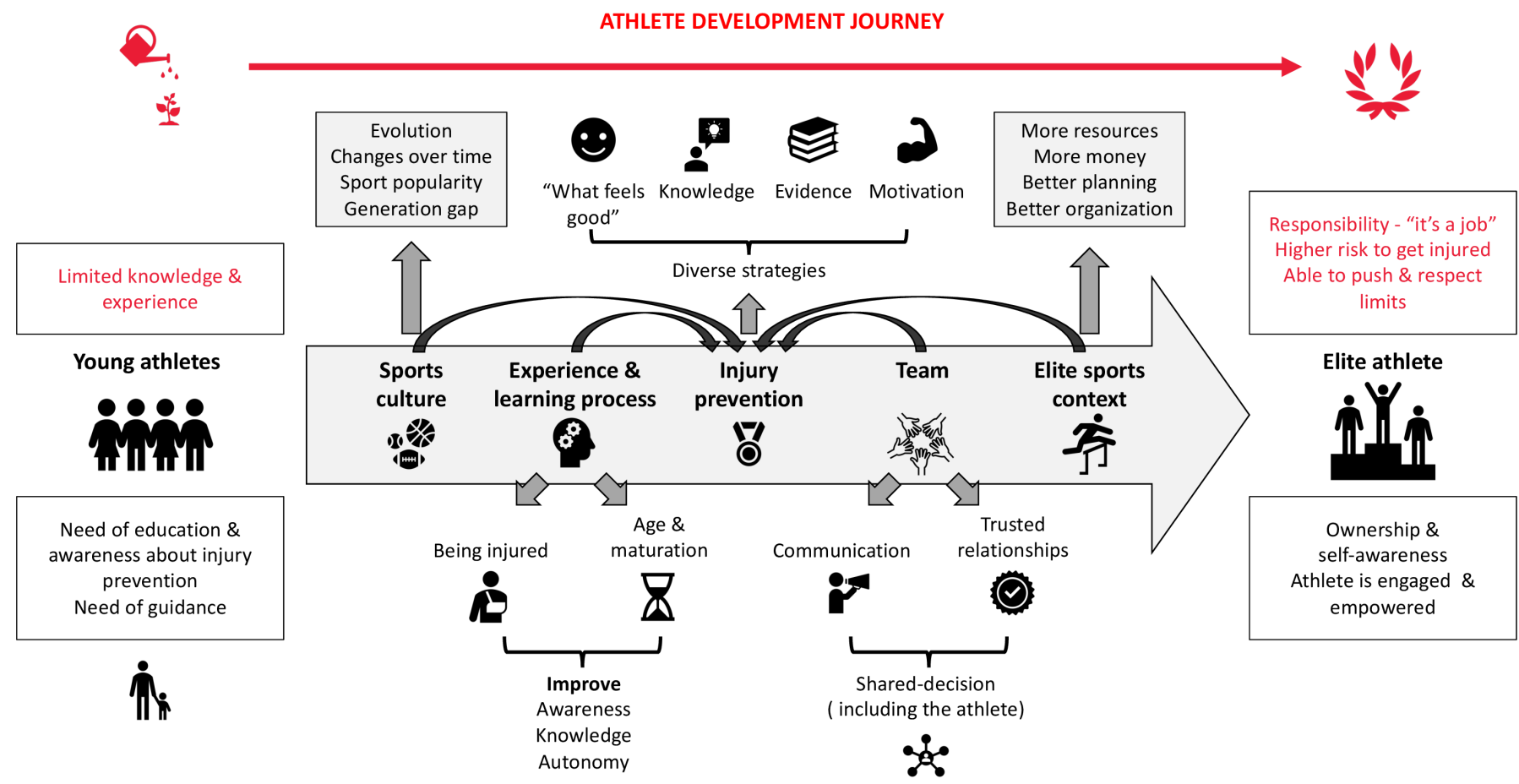

Figure 1 Following our data analysis, this figure summarizes the athletes' path from their early careers towards becoming elite athletes. In the first years, athletes have limited awareness and knowledge about injury prevention and need more guidance. The development process of an athlete is represented in the central arrow, which contains the main constructs that evolve during their athletic journey; sports culture, experience, injury prevention, teamwork, and elite context. In the centre of the process, injury prevention is influenced by the other constructs as well. At the end of the road, the elite athlete has more responsibility and a greater risk to get injured. Still, they are more actively engaged in injury prevention and push and respect their limits based on self-awareness. 
learning process in which age, maturity and previous injuries influenced injury prevention throughout their careers. Participants highlighted that this process was part of becoming an elite athlete, ${ }^{33}$ since they consistently compared their current behaviour with their previous preventive strategies from the past. The experience of sustaining injuries plays a role in this development of preventive behaviours. ${ }^{22}{ }^{33} 34$ Yet, the influence of experience in sports injury prevention has not been fully investigated in sports medicine.

Less experienced athletes take less responsibility when making decisions, signifying they need more guidance earlier in their careers. Meanwhile, experienced athletes have acquired more understanding and responsibility, which allows some autonomy and independence in their decisions around sports preventive strategies. ${ }^{34}$ Therefore, as suggested in return-to-sport literature, engaging and empowering athletes provides an athlete-centred approach that promotes the athlete's athletic, personal and professional development. ${ }^{35}$ Thus, different approaches should be considered when dealing with youth or experienced elite athletes. Nonetheless, further studies on the athlete's ownership within the injury prevention field are needed.

\section{Investing in education is needed: but for whom and how?}

Athletes emphasised the necessity of awareness and better education regarding injury prevention at their early career stages, facilitating their learning process. However, based on the results discussed, early-career athletes need a different preventive approach (and education) than later career athletes. Previous studies support the idea that this process also needs close supervision by all stakeholders who support the athlete. ${ }^{3637}$

The experienced athletes reported a more active role in their education and the decision-making process. Previous studies confirm our findings that athletes gained experience through trial and error, with their previous experiences shaping their current preventive behaviours. For young and less knowledgeable athletes, we must consider the relationships and interactions that impact their positive health behaviours, and extend the latter throughout their elite athletic career. ${ }^{36}$ It has also been suggested that rugby players of different ages should have different approaches for their education. ${ }^{38}$

Education in sports injury prevention is of utmost importance. For instance, providing athletes with educational resources greatly influenced rugby players' attitudes towards injury prevention. ${ }^{39}$ Although recent research has been conducted on the importance of knowledge and information in sports injury prevention, there is little literature regarding athletes' perspectives on education resources. Based on our results, different strategies regarding education should be taken based on the athlete's experience.

The culture around high-performance sports should also be considered. Previous studies focused on the sociocultural environment and its negative impact on injury risk, with athletes competing injured and accepting such behaviour as normal. ${ }^{41}{ }^{41}$ On the other hand, as our participants recognised the value of injury prevention that is needed to reach the elite level and the changes in culture compared with previous generations, our study indicates that it is possible to develop a positive culture of reducing injury risk through awareness and education.

\section{Contextuality of injury prevention: when, where, for whom and how?}

Athletes and staff compared the current sports and injury prevention situation with their earlier careers, mentioning evolution and generational gaps. The contemporary medical resources and professionalism were not always in place. Although participants defined and perceived injury alike, sports culture across athletes and their teams substantially influenced their awareness, willingness, adoption and implementation of injury prevention.

Our study reported the diversity in economic, structural, and personnel resources among sports and Belgian communities. However, such diversity is not exclusive to the Belgium context and should be considered when planning and implementing injury prevention strategies. A recent study showed medical service quality and access variations among international elite adolescent athletes from different countries. ${ }^{42}$ This diversity of resources and structure can impact the quality of care. This contrast in providing such resources suggests that only the fittest or the least injured athletes survive their elite journeys.

Athletes highlighted a mismatch in terms of resources. Young athletes had limited awareness of resources or access to information on injury prevention. Experienced elite athletes are better equipped than their younger, more inexperienced counterparts and have access to resources that they may not need to the full extent. Providing young athletes with more resources will allow them to develop athletically and personally, ${ }^{36} 43$ through education leading to injury awareness and procurement of strategies to lower injury risks. This supports the developing athlete to reach an elite level.

Given the dynamism and complexity of injury prevention strategies, creating a functional, collaborative interdisciplinary team is critical to share responsibility for developing and implementing preventive behaviours. ${ }^{7101144}$ Therefore, all stakeholders should be involved in injury prevention and be aware of the contextual factors around athletes that change over time.

\section{Methodological considerations}

The trustworthiness of our findings was reinforced by applying different methods. ${ }^{45}$ Data and investigator triangulation were employed for credibility by including different stakeholders such as athletes, coaches, managers and healthcare providers, and different researchers with different backgrounds and cultures conducting the data analysis process. Multiple meetings and discussions validated the analysis and the relationship with previous literature to increase confirmability. Regarding transferability, our participants comprise a diverse sample of Belgian Olympic level 
athletes and staff with diverse experience, backgrounds and cultures concerning injury prevention. This provided a broad insight into the complexity and dynamism of sports injury prevention. Still, we need to understand that these findings are contextual and circumstantial. Dependability was accomplished by creating an audit trail in which memos were written to record the development and reporting of the findings.

\section{CONCLUSION}

Our findings provide an insight into the contextual factors that influence sports injury prevention at an Olympic level. These results also bring practical implications on how we should approach injury prevention in different ways along the journey of becoming an elite athlete. Considering specific contextual factors and influencing the process through education, communication and shared responsibility is essential to develop a healthy and successful athlete. Future investigations should explore contextual factors of different sports, settings and levels to develop more comprehensive and context-driven injury prevention strategies.

\section{Twitter Evert Verhagen @evertverhagen and Caroline Bolling @cs_bolling}

Acknowledgements All authors that analysed data are trained and experienced in conducting qualitative research with athletes. OBM is a sports physiotherapist with experience in sports injury prevention. $\mathrm{CB}$ is also a sports physical therapist with experience in elite sports injuries and a postdoctoral researcher. EV is a sports scientist and epidemiologist with broad experience in injury prevention. The diversity of perspectives and backgrounds represented by the authors supports the rigour and trustworthiness of the findings. This study is part of a larger project involving 12 partners across the IOC Research Centres of Excellence (Canada, South Africa, Denmark, Australia, Belgium, and France (ReFORM - French-speaking Research Network for Athlete Health Protection \& Performance), South Korea, United Kingdom, Qatar, the Netherlands, Austria, United States of America). We would like to acknowledge the participants who participated in this study for their time.

Contributors $\mathrm{CB}$ and EV designed the study. $\mathrm{CB}$ coordinated the study. J-FK recruited athletes and staff. $\mathrm{OBM}$ and $\mathrm{CB}$ conducted the data analysis. $\mathrm{OBM}, \mathrm{CB}$ and EV interpreted the results. OBM drafted the first version. CB, J-FK and EV contributed intellectually and provided feedback on various drafts. After that, all authors were involved in editing the manuscript and approved the final manuscript. $\mathrm{EV}$ is the guarantor of this study, and responsible for the overall content.

Funding The authors have not declared a specific grant for this research from any funding agency in the public, commercial or not-for-profit sectors.

Competing interests EV is Editor in Chief of BMJ Open Sports \& Exercise Medicine.

Patient and public involvement Patients and/or the public were not involved in the design, reporting, or dissemination plans of this research. As this was a qualitative study, participants were invovled in the conduct of the research and the results present the participants' voice.

Patient consent for publication Consent obtained directly from patient(s)

Ethics approval Amsterdam UMC Ethics Committee. Protocol number 2020.2014.

Provenance and peer review Not commissioned; externally peer reviewed.

Data availability statement Data are available on reasonable request.

Open access This is an open access article distributed in accordance with the Creative Commons Attribution Non Commercial (CC BY-NC 4.0) license, which permits others to distribute, remix, adapt, build upon this work non-commercially, and license their derivative works on different terms, provided the original work is properly cited, appropriate credit is given, any changes made indicated, and the use is non-commercial. See: http://creativecommons.org/licenses/by-nc/4.0/.

\section{ORCID iD}

Evert Verhagen http://orcid.org/0000-0001-9227-8234

\section{REFERENCES}

1 Klügl M, Shrier I, McBain K, et al. The prevention of sport injury: an analysis of 12000 published manuscripts. Clin J Sport Med 2010;20:407-12.

2 Verhagen E, Gabbett T. Load, capacity and health: critical pieces of the holistic performance puzzle. Br J Sports Med 2019;53:5-6.

3 Drew MK, Raysmith BP, Charlton PC. Injuries impair the chance of successful performance by sportspeople: a systematic review. $\mathrm{Br} J$ Sports Med 2017:51:1209-14.

4 Bolling C, van Mechelen W, Pasman HR, et al. Context Matters: Revisiting the First Step of the 'Sequence of Prevention' of Sports Injuries. Sports Med 2018;48:2227-34.

5 Verhagen E. Get set: prevent sports injuries with exercise! Br J Sports Med 2015;49:762.

6 Chalmers DJ. Injury prevention in sport: not yet part of the game? Inj Prev 2002;8:22iv-5.

7 Finch C. A new framework for research leading to sports injury prevention. J Sci Med Sport 2006;9:3-9.

8 Bahr R, Thorborg K, Ekstrand J. Evidence-Based hamstring injury prevention is not adopted by the majority of champions League or Norwegian premier League football teams: the Nordic hamstring survey. Br J Sports Med 2015;49:1466-71.

9 Lindblom H, Carlfjord S, Hägglund M. Adoption and use of an injury prevention exercise program in female football: a qualitative study among coaches. Scand J Med Sci Sports 2018;28:1295-303.

10 Bittencourt NFN, Meeuwisse WH, Mendonça LD, et al. Complex systems approach for sports injuries: moving from risk factor identification to injury pattern recognition-narrative review and new concept. Br J Sports Med 2016;50:1309-14.

11 Bekker S, Clark AM. Bringing complexity to sports injury prevention research: from simplification to explanation. Br J Sports Med 2016;50:1489-90.

12 Hulme A, Finch CF. From monocausality to systems thinking: a complementary and alternative conceptual approach for better understanding the development and prevention of sports injury. Inj Epidemiol 2015;2:1-12.

13 Finch CF, Donaldson A. A sports setting matrix for understanding the implementation context for community sport. Br J Sports Med 2010;44:973-8

14 Verhagen E, Voogt N, Bruinsma A, et al. A knowledge transfer scheme to bridge the gap between science and practice: an integration of existing research frameworks into a tool for practice. Br J Sports Med 2014:48:698-701.

15 Verhagen E, Bolling C. We Dare to ask new questions. Are we also brave enough to change our approaches? Trans/ Sports Med 2018;1:54-5.

16 Verhagen EALM, van Stralen MM, van Mechelen W. Behaviour, the key factor for sports injury prevention. Sports Med 2010;40:899-906.

17 Barboza SD, Bolling CS, Nauta J, et al. Acceptability and perceptions of end-users towards an online sports-health surveillance system. BMJ Open Sport Exerc Med 2017:3:e000275

18 McCall A, Dupont G, Ekstrand J. Injury prevention strategies, coach compliance and player adherence of 33 of the UEFA elite Club injury study teams: a survey of teams' head medical officers. Br J Sports Med 2016;50:725-30.

19 Bolling C, van Rijn RM, Pasman HR, et al. In your shoes: a qualitative study on the perspectives of professional dancers and staff regarding dance injury and its prevention. Trans/ Sports Med 2021;4:386-94.

20 Bolling C, Delfino Barboza S, van Mechelen W, et al. How elite athletes, coaches, and physiotherapists perceive a sports injury. Trans/ Sports Med 2019;2:17-23.

21 Vella S, Bolling C, Verhagen E. Perceiving, reporting and managing an injury - perspectives from national team football players, coaches, and health professionals. Sci Med Footb 2021. [Epub ahead of print: 27 Sep 2021].

22 Bolling C, Delfino Barboza S, van Mechelen W, et al. Letting the cat out of the bag: athletes, coaches and physiotherapists share their perspectives on injury prevention in elite sports. Br J Sports Med 2020;54:871-7.

23 Rees H, Matthews J, McCarthy Persson U, et al. Coaches attitudes to injury and injury prevention: a qualitative study of Irish field hockey coaches. BMJ Open Sport Exerc Med 2021;7:e001074.

24 Jack SM. Utility of qualitative research findings in evidence-based public health practice. Public Health Nurs 2006;23:277-83.

25 Glaser BG, Strauss AL. Discovery of Grounded theory: strategies for qualitative research. Taylor and Francis, 2017.

26 Charmaz KC. Constructing grounded theory: a practical guide through qualitative analysis. Heal -LONDON-SAGE Publ 2006;10:378-80. 
27 Levers M-JD. Philosophical paradigms, grounded theory, and perspectives on emergence. SAGE Open 2013;3:215824401351724.

28 Tong A, Sainsbury P, Craig J. Consolidated criteria for reporting qualitative research (COREQ): a 32-item checklist for interviews and focus groups. Int J Qual Health Care 2007;19:349-57.

29 Coyne IT. Sampling in qualitative research. purposeful and theoretical sampling; merging or clear boundaries? J Adv Nurs 1997;26:623-30

30 Saunders B, Sim J, Kingstone T, et al. Saturation in qualitative research: exploring its conceptualization and operationalization. Qual Quant 2018;52:1893-907.

31 Glaser BG. The constant comparative method of qualitative analysis Soc Probl VO - 12 1965;445:436 http://ludwig.lub.lu.se/login?url= http://search.ebscohost.com/login.aspx?direct=true\&db=edsjsr\& $\mathrm{AN}=$ edsjsr $.798843 \&$ site $=$ eds-live $\&$ scope $=$ site

32 Boeije $\mathrm{H}$. A purposeful approach to the constant comparative method in the analysis of qualitative interviews. Qual Quant 2002;36:391-409.

33 Sarkar M, Fletcher D, Brown DJ. What doesn't kill me...: Adversityrelated experiences are vital in the development of superior Olympic performance. J Sci Med Sport 2015;18:475-9.

34 Kristiansen JB, Larsson I. Elite professional soccer players' experience of injury prevention. Cogent Med 2017:4:1389257-15.

35 King J, Roberts C, Hard S, et al. Want to improve return to sport outcomes following injury? Empower, engage, provide feedback and be transparent: 4 habits! Br J Sports Med 2019;53:526-7.

36 Jacobsson J, Bergin D, Timpka T, et al. Injuries in youth track and field are perceived to have multiple-level causes that call for ecological (holistic-developmental) interventions: a national sporting community perceptions and experiences. Scand J Med Sci Sports 2018;28:348-55.
37 White P, Donaldson A, Finch CF. But can someone like me do it? The importance of appropriate role modelling for safety behaviours in sports injury prevention. Br J Sports Med 2016;50:569-70.

38 Brown JC, Gardner-Lubbe S, Lambert MI, et al. Coach-directed education is associated with injury-prevention behaviour in players: an ecological cross-sectional study. Br J Sports Med 2018:52:989-93.

39 Hendricks S, den Hollander S, Lambert M. Coaching behaviours and learning resources; influence on rugby players' attitudes towards injury prevention and performance in the tackle. Science and Medicine in Football 2020;4:10-14.

40 Hausken-Sutter SE, Pringle R, Schubring A, et al. Youth sport injury research: a narrative review and the potential of interdisciplinarity. BMJ Open Sport Exerc Med 2021;7:e000933.

41 Ivarsson A, Johnson U, Karlsson J, et al. Elite female footballers' stories of sociocultural factors, emotions, and behaviours prior to anterior cruciate ligament injury. International Journal of Sport and Exercise Psychology 2019;17:630-46.

42 Timpka T, Fagher K, Bargoria V, et al. 'The little engine that could': a qualitative study of medical service access and effectiveness among adolescent athletics athletes competing at the highest international level. Int J Environ Res Public Health 2021;18:7278.

43 Bahr R. Demise of the fittest: are we destroying our biggest talents? Br J Sports Med 2014;48:1265-7.

44 Bolling C, Mellette J, Pasman HR, et al. From the safety net to the injury prevention web: applying systems thinking to unravel injury prevention challenges and opportunities in Cirque Du SOLEIL. BMJ Open Sport Exerc Med 2019;5:e000492-9.

45 Korstjens I, Moser A. Series: practical guidance to qualitative research. Part 4: Trustworthiness and publishing. Eur J Gen Pract 2018;24:120-4. 